\title{
Isolated unilateral hemispheric cerebellar hypoplasia
}

INSERM

\section{Source}

INSERM. (1999). Orphanet: an online rare disease and orphan drug data base. Isolated unilateral hemispheric cerebellar hypoplasia. ORPHA:269218

Isolated unilateral hemispheric cerebellar hypoplasia is a rare, non-syndromic cerebellar malformation characterized by loss of volume in the right or left cerebellar hemisphere, with intact vermis and no other neurological anomalies (i.e. normal cerebral hemispheres, fourth ventricle, pons, medulla and midbrain). Patients may be asymptomatic or may present developmental and speech delay, hypotonia, abnormal ocular movements, persistent headaches and/or peripheral vertigo and ataxia. Neurological examination is otherwise normal. 